\title{
A NEW WAY OF ENGAGING COASTAL STAKEHOLDERS: COASTRANGER MS
}

\begin{abstract}
N. Pontee', B. Hamer'2, K. Morris ${ }^{3}$
The management of coastal change involves a range of stakeholders, ranging from local residents to government officials, whose backgrounds and expertise differ widely. It is necessary that these stakeholders understand the nature of future coastal changes and their potential impacts. This paper describes an innovative approach that has been developed to stimulate public debate and improve stakeholder understanding of the issues that need to be balanced in order to achieve sustainable long term coastal management solutions. The approach involves the creation of an educational tool (CoastRanger $M S$ ) that allows users to manage a virtual coast within a pc-gaming type environment.
\end{abstract}

Key words: Virtual, Simulator, Shoreline management, Climate change, Flood risk, Erosion risk

\section{INTRODUCTION}

In a number of countries, long term strategic management plans are being developed to deal with the impacts arising from coastal change. Experience in developing these plans for in both the US and UK has highlighted the importance of successful programs for stakeholder engagement. It is critically important to involve the public, staff in local authorities, such as planners, and local politicians, in order to foster understanding and ensure the adoption of the recommended solutions.

This paper describes an innovative approach that has been developed to stimulate public debate and improve stakeholder understanding of the issues that need to be balanced in order to achieve sustainable long term coastal management solutions. The approach, which has been funded under the UK Government 'Making Space for Water' strategy (Defra, 2005), involves the creation of an educational tool (CoastRanger $M S$ ) that allows users to manage a virtual coast within a pc-gaming type environment (Figure 1). The tool explains the nature of the likely future changes and the impacts that these will have upon coastal communities. The tool allows users to explore the consequences that different management approaches have on coastal processes, natural environments and flood and coastal erosion risk. The tool incorporates a legacy of past developments and defences, and uses a coastal process simulator to predict the impacts of climate change under different management scenarios chosen by the user.

This paper will show how CoastRanger $M S$ highlights a number of key coastal management issues, including:

- the response of the coast to rising sea levels and the likelihood of increasing flood and erosion risk;

\footnotetext{
${ }^{1}$ Halcrow, Burderop Park, Swindon, Wiltshire, UK, SN40QD

${ }^{2}$ Halcrow, Burderop Park, Swindon, Wiltshire, UK, SN40QD

${ }^{3}$ Discovery Software Ltd, Paignton, Devon, UK, TQ47DA
} 
- the importance of beaches as natural flood defences;

- the importance of eroding cliffs as sediment sources for these beaches;

- the need to prioritise spending on sea defences to making best use of limited budgets; and,

- the consequences of defending/not defending the coast in terms of the natural and built environment.

The paper also describes the target audience for the tool and gives several examples of how the tool is being used within the UK to assist in stakeholder engagement. Finally, the paper shows how the principles behind CoastRanger MS could be developed for use in other countries around the world where coastal zone management is a key issue.

\section{WHY SOFTWARE?}

Software packages can achieve more than written reports or verbal presentations by allowing users to become more involved with the issues as they attempt to solve problems for themselves. This process avoids simply stating the problems and presenting the solutions. Instead, users see for themselves the advantages and disadvantages of various coastal management options under a scenario of rising sea levels, limited sediment supply and a predominance of erosion.

The virtual environment allows the impacts of the various management options to be seen in terms of not only properties and economics, but also habitats and social well being. This approach allows users to review the consequences of their decisions, learn from them and try different approaches next time they use the software. In this way, it is hoped that users gain a better understanding of why preferred management options are chosen in a real world situation.

Additionally the software provides a platform for presenting supporting information on coastal processes and management and provides links to further information sources such as literature and websites.

Since the software is self contained and requires no prior knowledge, it can be used by a range of stakeholders. Such an approach should be particularly useful in reaching people deterred by tradition auditory learning styles. In relation to this point, Gill et al. (2001) suggest that software approaches can greatly increase stakeholders feelings of ownership over the process of planning on the coast. 


\section{OVERVIEW OF SOFTWARE}

The software is opened from a front screen (Figure 1). This front end screen allows users to:

- $\quad$ start the management simulator;

- $\quad$ view a quick start tutorial video;

- open User Instructions and a Technical Background document; and,

- view a PowerPoint presentation.

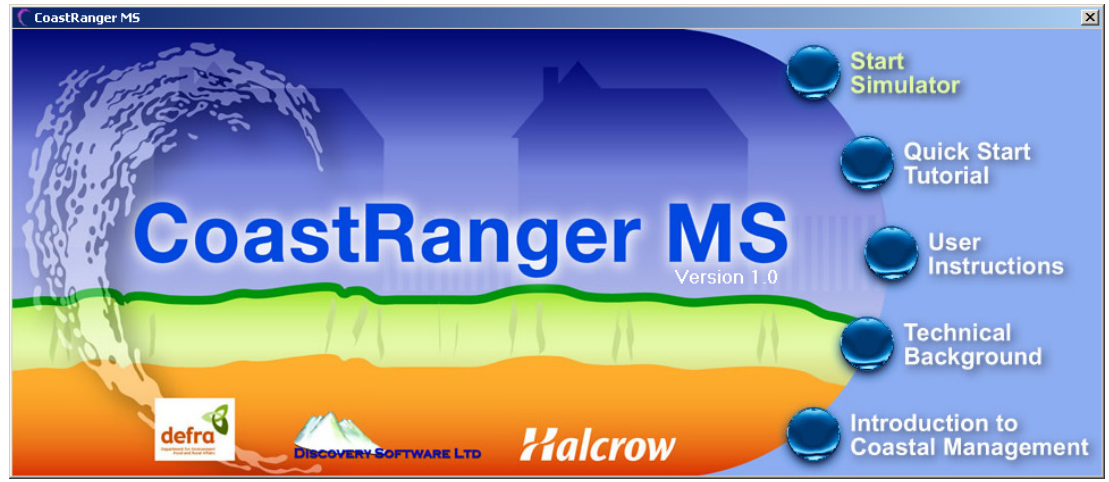

Figure 1: Front screen of CoastRanger MS. Users can access various supporting information files or run the software 
The User Instructions document provides a brief introduction to CoastRanger $M S$ and how to use it. The Technical Background document explains the issues associated with coastal management in the UK, the purpose of CoastRanger MS and the key technical assumptions that lie behind it. This document also provides links to other documents and websites. The PowerPoint presentation that provides an introduction to coastal processes and management.

The management simulator aspect of CoastRanger $M S$ is based on a virtual coastline which is some $16 \mathrm{~km}$ in length and is comprised of eroding soft cliffs, coastal villages, towns and agricultural land. There are a number of heritage sites situated along the coast and several environmentally designated areas including dunes, terrestrial cliff habitats and wetland areas. The software allows users to explore the consequences that different management approaches have on coastal processes, natural environments and flood and coastal erosion risk. Figure 2 shows that user interface within the software itself.

Within CoastRanger MS users are required to:

- manage flood and coastal erosion risk levels to various features by choosing different management options;

- maintain / restore / improve natural and historic environments by choosing different defence options;

- $\quad$ provide social facilities by adding housing, hospitals, and schools for an expanding population;

- $\quad$ provide employment for an expanding population by adding industrial facilities; and,

- $\quad$ keep financial expenditure within allocated budgets.

CoastRanger MS simulates policy development over 100 years concurrent with the latest UK Government guidance. This period is divided up into 10 year epochs. The software generates various results to show users how well they have done over each epoch and whether or not their management choices have allowed people to become homeless or unemployed, or their properties to be flooded or eroded.

CoastRanger $M S$ can be used in a number of ways and example tutorials (described in the User Instructions) take between 30 minutes and 2 hours. After this time users should have an understanding of:

- the need to balance economic, social and environmental needs; 
- the need to plan over the long term; and,

- the potential impacts of climate change on the coast.

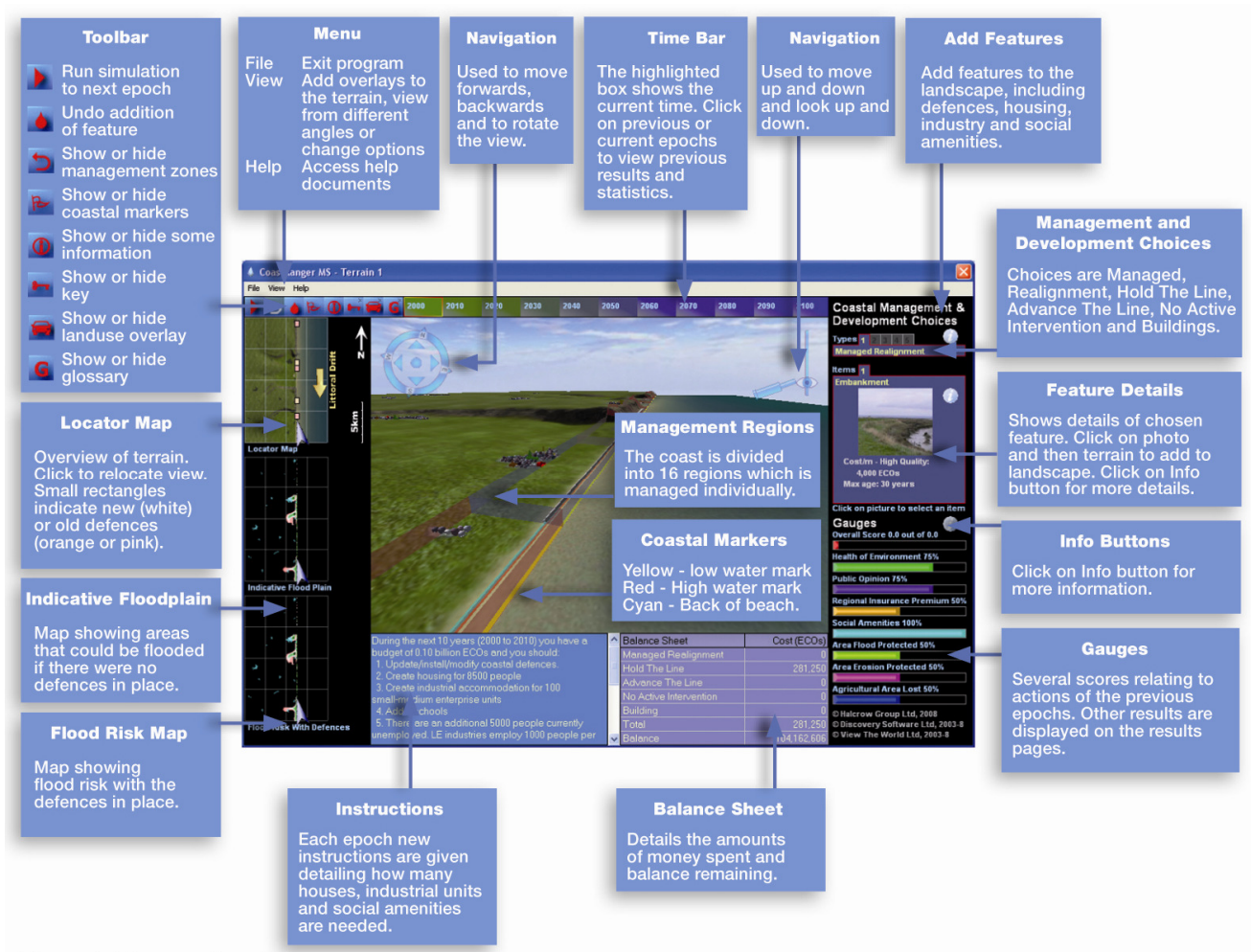

Figure 2: User interface within CoastRanger MS

\section{KEY MESSAGES AND INFORMATION ROUTES}

The CoastRanger MS software was specifically developed to make coastal stakeholders aware of certain key issues:

- the risks from flooding and erosion facing people and the developed, historic and natural environment along typical coastlines under rising sea levels;

- the complexity of managing the coastline in order to satisfy the maximum number of objectives of different user groups;

- the impacts of different management options on properties, infrastructure, habitats and social wellbeing; 
- the impacts of sea level rise and coastal defences on coastal processes;

- the requirement to protect natural habitats under national or international law, including the requirement to provide compensatory habitat; and,

- the limited financial resources available to cover flood and coastal erosion risk management and other social requirements.

Within the software, these key messages are conveyed in variety of ways:

- a PowerPoint presentation;

- results tables listing losses and gains of houses, property and other assets;

- gauges for the health of the environment, public opinion, social amenities, areas protected from flooding and erosion, and area of agricultural land lost;

- $\quad$ animations of coastal change;

- $\quad$ pop up text messages;

- (1) buttons which lead to further information;

- a glossary which provides definitions of key terms; and,

- $\quad$ supporting documentation.

The PowerPoint presentation provides an introduction to coastal management and an illustration of real world problems and covers:

- $\quad$ typical problems;

- coastal processes;

- coastal evolution;

- $\quad$ coastal management policy options;

- how policies are developed;

- current legislation; and,

- $\quad$ planning processes.

The consequences of different management options on properties, infrastructure, habitats and social wellbeing are highlighted throughout the simulation in a number of different ways, including: gauges, pop up messages and results pages. Flooding and erosion risks are also highlighted by pop up messages which appear if users try to position new built assets in areas of flood or erosion risk. Particular efforts were made to ensure that one of the results pages within CoastRanger MS presented information in a similar manner to UK Shoreline Management Plans (SMPs; Figure 
3). This highlights the loss of buildings and agricultural land - issues that stakeholders are typically uppermost in the minds of local stakeholders.

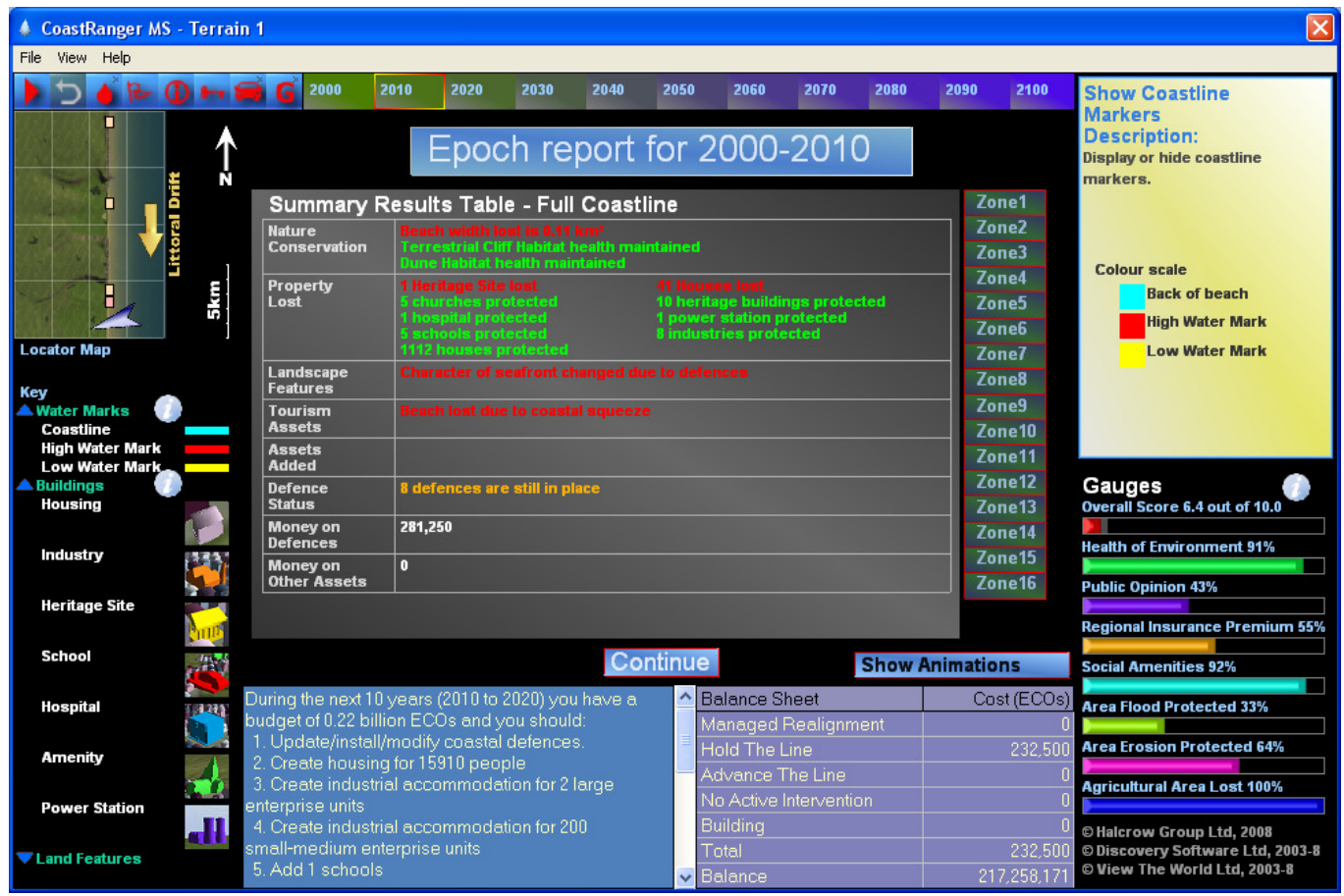

Figure 3: Summary results table showing the loss/gain of different coastal assets

During the development of the software, a stakeholder workshop identified that people found the animations of coastal change particularly valuable. The animations are particularly useful in highlighting the effect of defending or not defending sections of coast over a 100 year timeframe under a scenario of rising sea levels. For example, the continued defence of eroding coasts leads to the loss of beaches, increasing defence costs and, eventually, the formation of headlands with consequent downdrift erosion. If no defences are present then the coast migrates landwards leading to the loss of built assets and displacement of habitats.

The value of eroding cliffs as sediment sources for these beaches is captured within the coastal process simulator, which ensures that if cliffs are defended there is accelerated erosion of beaches downdrift and the loss of beaches in front of the defended section. Additionally, pop up messages stating the importance of cliffs as suppliers of sediment to beaches appear if users try to defend eroding cliffs.

The requirements to protect natural habitats under national or international law, including the requirement to provide compensatory habitat, are highlighted within the 
software by pop up messages and information on various environment designations which is accessed by clicking on (1) buttons.

Users are made aware of the limited financial resources by provision of a limited budget in each epoch which is insufficient to defend the entire coastline whilst still providing adequate social facilities, housing and industry. A balance sheet calculates the remaining budget in each epoch. If users fail to provide adequate housing, industry or defences then a warning message appears.

Within the software (1) buttons provide more information on a number of aspects:

- Coastal management policies (Defra, 2006): Hold the Line, Advance the Line, Managed realignment, and Advance the Line. For each of these policies, the information provides a description and method of implementation; an explanation of where the policy is typically implemented, and a description of the implications of the policy over time;

- Engineering options to implement the 4 coastal management policies, including: seawalls, revetment, offshore breakwaters, groynes, and beach recharge. Information is presented on the function/impacts of the option and the different options for the quality of defence in terms of design, standard of flood protection cost;

- Natural environments including: sandy beaches, dunes, barrier beaches, cliffs and freshwater marshes. Information is presented on the physical behaviour of each environment, its interactions with other environments and its sensitivity to climate change; and,

- Environmental, heritage and landscape designations (e.g. Special Areas of Conservation (SACs), Sites of Special Scientific Interest (SSSIs) etc) are described briefly in terms of their purpose and importance.

Within the software, a glossary defines 98 terms commonly used in coastal management many of which are mentioned within the software or supporting documents. Table 1 provides an example of the type of information presented in the glossary.

Table 1: Examples of information presented in the glossary.

Coastal processes Collective term covering the action of natural forces on the shoreline and nearshore seabed. 
Coastal squeeze $\quad$ Narrowing of the intertidal zone and reduction of habitat due to the prevention of its natural landward migration, in response to sea-level rise, e.g. by permanent barriers fixing the high water mark (humanbuilt or natural).

TARGET AUDIENCE

It is intended that the tool can be used by a range of audiences, including:

- The general public, including home owners, agricultural land owners, local business owners, environmental groups;

- Educational establishments, including students of ICZM/Coastal engineering and planning at both 'A' level and university levels;

- Coastal managers, including local authorities, county and district councillors, coastal managers, maintenance teams, coastal managers and planners, elected members and staff of Natural England; and,

- Coastal Planners, including regional and local planners, emergency services/planners and critical infrastructure operators.

It is likely that different audiences will use the tool in different ways. However, experience with previous educational games suggests that the greatest benefits can be gained through using the tool as part of an organised workshop (CIWEM, 2006) where users can discuss their experiences/understanding in a group setting and thus gain a wider appreciation of the issues associated with managing the coast.

To carefully appraise each available management options for each stretch of coast for each decade of the simulation may take users several hours. However, it is not necessary to run the whole simulation over 100 years or even to manage the whole frontage in order to gain an appreciation of the issues involved with managing the coast. If less time is available to users, then it is possible to concentrate on choosing different management options for individual lengths of coast for a few decade decades. In this instance pop up messages and scores help convey the consequences of the different management options.

To date, copies of CoastRanger MS have been distributed to staff in a number of local authorities and government agencies responsible for shoreline management throughout the UK. The Environment Agency has purchased a number of copies of the software for use by its coastal community liaison officers who are spearheading a strategy to engage with local communities that are likely to be affected by coastal change in the future. Promotional copies of the software have also been issued to a number of other countries including the Netherlands, the USA and Switzerland.

\section{SCOPE FOR DEVELOPMENT}

A number of opportunities exist to extend the functionality of the tool including: 
- the incorporation of alternative generic coastal settings and climate change scenarios;

- the addition of more defined parameters such as budgets, population, land types, environment, infrastructure etc;

- increased functionality to compare chosen management options with a do nothing baseline;

- $\quad$ the incorporation of different policy approaches; (e.g. adaptation measures);

- the development of web based version of the tool, possibly to allow multiple players; and,

- the development of a real world simulation.

\section{CONCLUSIONS}

CoastRanger MS explains the nature of the likely future changes and the impacts that these will have upon coastal communities. In particular, the software explains the consequences that different management approaches have on coastal processes, natural environments and flood and coastal erosion risk. The software also highlights the range of interests that need to be balanced on the coast and demonstrates the difficult decisions that have to be made in some areas. CoastRanger MS simulates typical real world scenarios and provides information on management approaches, defence types, coastal behaviour and legislation. Within the software users can access additional information via information buttons, a PowerPoint presentation and a glossary. Further background information is contained with accompanying printed documents.

The software is intended to appeal to a wide range of audiences including:

- people that live, work and play on the coast;

- professionals involved in the management of the coast; and,

- students of coastal management in schools and universities.

It is anticipated that the tool will be of particular value in educating stakeholders before and during the development of SMPs and strategies. The software is likely to be particularly valuable at the outset of such projects, as a way of making stakeholders aware of the various issues that need to be balanced. The expectation is that CoastRanger $M S$ will prove to be a helpful tool in educating the public and other stakeholders on the complexities of shoreline management and allow better informed debate and more effective consultations in the future. The software has the potential to be developed further and used in other parts of the world.

\section{REFERENCES}

CIWEM, 2006. Taking managed realignment forward as a policy option for coastal management in England and Wales. A CIWEM briefing report. October 2006. 24pp. 
Available online at www.ciwem.org/resources/ciwem_briefing report_management realignment.doc.

CoastRanger MS, 2009. Software Version 1.0. Document Revision 1.0, February 2009. For further information contact Nigel Pontee at Halcrow, ponteeni@halcrow.com or visit website:

http://www.discoverysoftware.co.uk/CoastRangerMS.htm

Defra, 2005. Making Space for Water: Flood \& Coastal Erosion Risk Management Innovation Fund. Project description available online at:

http://www.defra.gov.uk/environment/flooding/risk/innovation/index.htm

Accessed 15 June 2010.

Gill, J., O'Riordan, T., and Watkinson, A., 2001. Redesigning the Coast - Science Workshop. Organised by the Tyndall Centre for Climate Change Research and the Centre for Social and Economic Research on the Global Environment, October 2001. Tyndall Centre for Climate Change Research, Norwich, UK. 